\title{
DIRASAH
}

Volume 2, Number 1, Februari 2019

p-ISSN: 2615-0212 | e-ISSN: 2621-2838

https://ejournal.iaifa.ac.id/index.php/dirasah

\begin{tabular}{|c|c|c|}
\hline Accepted: & Revised: & Published: \\
Desember 2018 & Januari 2019 & Februari 2019 \\
\hline
\end{tabular}

\section{Karakteristik Pendidikan Luqman Hakim dalam Al-Qur'an Surat Luqman Ayat 13-17}

\author{
Ahmad Fauzi \\ Institut Agama Islam Faqih Asy'ari Kediri, Indonesia \\ e-mail: ahmadfauzi068@gmail.com
}

\begin{abstract}
The main reference in the concept of Islamic education is the Qur'an in surah Luqman, which is a letter that is referred to the name of a man who activity and wise in educating his son. He has a concept of education that can build spiritual intelligence in the child, so that Allaah perpetuates some words that contain wisdom from them in the Qur'an, so that they can be learned from the lessons and benefits. Using the Library study method, the study found that the education characteristic of Luqman Hakim as contained in the letter of Luqman verses 13-17, namely: (1) The education of Luqman Hakim about the Tauhid such as prohibition of shirk (purification of the soul of haughty and prideful nature); (2) Individualized morality such as gratitude, patience, safeguarding, doing good to parents and establishing prayers. (3) Social morality that is implemented with the practice of Amar Ma'ruf nahi Munkar.
\end{abstract}

Keywords: Education, Luqman Hakim, Surat Luqman verse 13-17 


\section{Pendahuluan}

Pendidikan tidak semata-mata berusaha untuk mencapai hasil belajar, akan tetapi bagaimana memperoleh hasil atau proses belajar yang terjadi pada diri anak. Dengan demikian, dalam pendidikan antara proses dan hasil belajar harus berjalan secara seimbang, pendidikan yang hanya mementingkan salah satu di antaranya tidak akan dapat membentuk manusia berkembang secara utuh. ${ }^{1}$

Sebagai rujukan utama dalam konsep pendidikan Islam adalah Al-Qur'an surat Luqman, yaitu surat yang di nisbatkan pada nama Seorang yang Sholih dan bijaksana dalam mendidik anaknya. Beliau memiliki konsep pendidikan yang dapat membangun kecerdasan spiritual pada anak, sehingga Allah ta'ala mengabadikan beberapa perkataan yang mengandung hikmah darinya dalam Al Qur'an, supaya dapat dipetik pelajaran dan manfaat darinya. Menurut Syaikh Abdurrazaq bin Abdul Muhsin Al Abbad hafidzahumallah menyatakan bahwa: "dia adalah seorang hamba sholih dan bukan seorang Nabi". Tidak terdapat di dalam Al Qur'an dan Sunnah Nabi shallallahu 'alaihi wa sallam yang menunjukkan bahwa dia seorang Nabi. Bahkan Imam Al Baghawi rahimahullah di dalam Ma'aalim At Tanziil : 3/490 menyatakan bahwa para ulama' telah bersepakat dia bukan seorang Nabi. Sebagai berikut: "Para ulama' telah bersepakat bahwa dia adalah orang yang bijaksana dan bukanlah seorang Nabi, kecuali Ikrimah, beliau menyatakan bahwa Luqman adalah seorang Nabi, beliau bersendirian dalam pendapatnya ini."2

Melihat cukup luasnya obyek penelitian, maka untuk lebih memperjelas dan memberi arah yang tepat dalam penulisan skripsi ini perlu adanya fokus kajian dalam pembahasannya. Dari sini, penulis membatasi ruang lingkup permasalahan dalam penelitian ini, yaitu bagaimana karakteristik pendidikan Luqman Hakim pada anak-anaknya dalam al-Qur'an surat Luqman ayat 13-17?

Fokus penelitian dari implikasi paedagogis di sini adalah surat Luqman ayat 13-17 yakni wahyu Allah yang diturunkan kepada Nabi Muhammad SAW dengan perantara malaikat Jibril yang mengandung tentang nasihat Luqman kepada anaknya untuk tidak mensekutukan Allah yang mana hal tersebut memberikan isyarat paedagogis tentang pentingnya materi tauhid dan materi akhlak yang harus di terapkan oleh pendidik terhadap peserta didik.

\footnotetext{
${ }^{1}$ Wina Sanjaya, Strategi pembelajaran (Jakarta: Kencana Prenada Group, 2008), 27.

${ }^{2}$ Imam Al Baghawi "Pendidikan Luqman", Republika on line, http://www. Republika.co. id, diakses tanggal 8 juni 2012.
} 
Adapun kegunaan dari hasil penelitian ini secara teoritis untuk mengembangkan ilmu pendidikan, khususnya bagi penulis umumnya bagi para pendidik, untuk memberikan gambaran tentang cara mendidik anak dengan baik di dalam lingkungan keluarga dan lingkungan formal. Sedangkan secara praktis untuk mengsosialisasikan tentang pentingnya pendidikan dalam keluarga dan formal menurut Al-Qur'an surat Luqman ayat 13-17, hal ini diharapkan dapat memberikan pemahaman pengetahuan yang sangat berguna bagi masyarakat luas.

\section{Metode Penelitian}

Metode penelitian kepustakaan atau metode kajian pustaka adalah strategi umum yang dianut dalam pengumpulan dan analisis data yang diperlukan, guna menjawab persoalan yang dihadapi. Dalam penelitian ini digunakan metode kajian kepustakaan (library research) sebagai metode penelitian dan pembahasan, yaitu mengumpulkan data dan informasi dengan bantuan bermacam-macam materi yang terdapat di ruang perpustakaan, seperti bukubuku, majalah, dokumen catatan dari kisah sejarah dan lain-lain. ${ }^{3}$

Metode penelitian pustaka dibatasi dalam hal-hal sebagai berikut:

1. Jenis Kajian

Dalam kajian ini, yang akan dilakukan adalah menelaah dokumendokumen dan sumber-sumber yang informasinya berkaitan dengan fokus kajian. Dari sini, peneliti akan membandingkan dan menyesuaikan antara sumber satu dengan sumber yang lainnya. Selanjutnya adalah menyimpulkan dari berbagai sumber tersebut.

Dalam kajian ini, peneliti akan memaparkan apa adanya sesuatu yang dimaksud oleh teks dengan cara mengungkapkan dengan bahasa peneliti sendiri. Maksudnya memaparkan apa adanya fakta dari suatu objek kajian tanpa mengurangi, menyalahkan bahkan menambahi. Kemudian menganalisis sesuai dengan bahasa sendiri.

2. Sumber Data

Sumber data adalah subyek dari mana data dapat diperoleh. Karena penelitian ini merupakan penelitian kepustakaan, maka dokumentasi atau

\footnotetext{
${ }^{3}$ Mardalis, Metode Penelitian Suatu Pendekatan Proposal (Jakarta, Bumi Aksara, 1995), 28.
}

Dirasah, Vol. 2, No. 1, Februari 2019 
catatan lah yang merupakan sumber datanya, sementara isinya adalah subyek penelitiannya. ${ }^{4}$ Dalam hal ini, sumber data terbagi menjadi dua yaitu:

a. Sumber Data Primer

Sumber ini biasanya merupakan penyajian formal pertama dari hasil penelitian dalam literatur tercetak atau elektronik yang menyajikan informasi dalam bentuk asli, tidak diinterpretasi maupun diringkas atau dievaluasi oleh penulis lain, menyajikan pemikiran orisinil, melaporkan penemuan, atau berbagai informasi baru. ${ }^{5}$ Dalam penelitian ini, sumber data primernya adalah sebagai berikut.

1) Tim DEPAG. al-Qur'an dan terjemahnya, (Bandung: Diponegoro, 2000).

2) Jalaluddin al-Mahalli dan Jalaluddin al-Suyuthi. Tafsir al-Jalalain. Maktabah Syāmilah (CD-ROM: Maktabah Syāmilah, Digital, t.t.).

3) Abdullah al-Ghamidi. Cara mengajar Anak/Murid ala Luqman alHakim. (Jogjakarta: Sabil, 2011).

b. Sumber Data Sekunder

Sumber data sekunder adalah sumber data yang sifatnya mendeskripsikan, menginterpretasi, menganalisis dan mengevaluasi sumber primer, memberi komentar (mengulas) dan membahas bukti-bukti dari sumber primer. ${ }^{6}$ Dalam penelitian ini, sumber data sekundernya adalah:

1) Ahmad Warson Munawwir. al-Munawwir: Kamus Arab-Indonesia. Yogyakarta: Pustaka Progressif, 1997.

2) Al-Suyuthy. Kronologis Hadis Asbabul Hadis. Terj. Yudi Junaedi. Jakarta: Nur Ihsani, 2003.

3) Jalālu ad-Dīni as-Suyūthī. al-Jāmi'u aṣ-Ṣaghīr. Surabaya: al-Hidayah, t.t..

4) Kementerian Urusan Agama Islam Wakaf, Da'wah, dan Irsyad Kerajaan Saudi Arabia. Al-Qur'an dan Terjemahannya. Madīnah: Mujamma' Malik Fahd li Thibā'āt al-Mușhaf as-Syarīf, 1997.

\footnotetext{
${ }^{4}$ Suharsimi Arikunto, Prosedur Penelitian: Suatu Pendekatan Praktek (Jakarta: Rineka Cipta, 1997), 107.

${ }^{5}$ Ward Saylor \& Helen Hooper, Sumber Primer, Sekunder \& Tersier, terj. Darmanto (t.t., t.p., t.t.), 1.

${ }^{6}$ Ibid., 2.
} 
5) Mardalis. Metode Penelitian Suatu Pendekatan Proposal, Jakarta, Bumi Aksara, 1995.

6) Maurice J. Elias, dkk. Cara-Cara Efektif Mengasuh Anak dengan EQ: Mengapa Penting Membina Disiplin Diri, Tanggung Jawab, dan Kesehatan Emosional Anak-Anak pada Masa Kini. Terj. M. Jauharul Fuad. Bandung: Kaifa, 2003.

7) Muhammad bin Qāsim. Fatḥ al-Qarīb al-Mujīb. Semarang: Thoha Putra, t.t..

8) Pusat Bahasa. Kamus Bahasa Indonesia. Jakarta: Departemen Pendidikan Nasional, 2008.

9) Ramayulis. Ilmu Pendidikan Islam. Jakarta: Kalam Mulia, 2008.

10) Salsa Az-Zahra. 101 Tips \& Ide Membimbing Spiritualitas Anak. Yogyakarta: Darul Hikmah, 2009.

11) Sururin. Ilmu Jiwa Agama. Jakarta: PT Raja Grafindo Persada, 2004.

12) W. A. Gerungan. Psikologi Sosial. Bandung: PT Rafika Aditama, 2004.

13) Zainuddīn bin Abdul Azīz al-Malībārī. Fath al-Mu'īn. Surabaya: alHidayah, t.t..

14) Dan buku-buku lain yang relevan.

c. Teknik Pengumpulan Data

Metode pengumpulan data yang dipakai dalam penelitian ini adalah metode dokumenter, yaitu mencari data mengenai hal-hal atau variabel yang berupa catatan, transkip, buku, surat kabar, majalah, prasasti, leger, agenda dan sebagainya. (Suharsimi Arikunto, 1998 247). Metode ini dipandang relevan untuk memperoleh data yang bersumber dari buku sebagai sumber utama penelitian ini.

3. Teknik Analisis Data

Setelah semua data dan bahan terkumpul, selanjutnya adalah menganalisisnya. Seluruh data yang ada akan dianalisis dengan metode analisis komparatif.

Metode Analisis Komparatif adalah sebuah metode analisis yang dapat menemukan persamaan-persamaan dan perbedaan-perbedaan tentang bendabenda, tentang orang, tentang prosedur kerja, tentang ide-ide, kritik terhadap orang, kelompok, terhadap suatu ide, atau suatu prosedur kerja. ${ }^{7}$ Atau

\footnotetext{
${ }^{7}$ Aswarni Sudjud dalam Suharsimi Arikunto, Prosedur Penelitian, 236.
}

Dirasah, Vol. 2, No. 1, Februari 2019 
membandingkan kesamaan pandangan dan perubahan-perubahan pandangan orang, grup, atau negara, terhadap kasus, terhadap orang, peristiwa, atau terhadap ide-ide. ${ }^{8}$

\section{Pembahasan}

\section{Interpretasi dan analisis tafsir al-qur'an surat luqman ayat 13-17}

Penulis akan mengkaji ayat-ayat surat Luqman yang bersinggungan mengenai hubungan Luqman dengan anaknya. Dari pembacaan dan pengamatan beserta pangkajian terhadap ayat-ayat surat Luqman, penulis hanya mengambil lima ayat untuk di jadikan kajian dalam skripsi ini. Berhubungan dengan konsep pendidikan akhlak yang dipesankan Allah SWT melalui lisan Luqman, dibawah ini akan dibahas lima ayat tersebut melalui penjelasan para penafsir. Dari kajian ayat-ayat ini diharapkan dapat diambil intisari pelajaran dalam rangka upaya bagaimana relevansinya terhadap pendidikan dalam aspek-aspek kecerdasan spiritual.

\section{1. tafsir QS Luqman ayat 13}

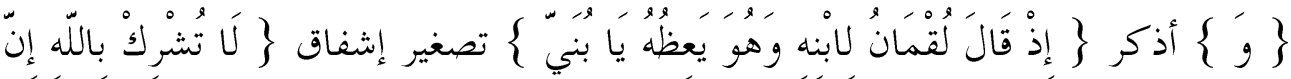

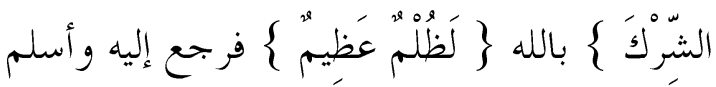

Artinya: “(Dan) ingatlah (ketika Luqman berkata kepada anaknya, di waktu ia menasihatinya, "Hai anakku) lafal bunayya adalah bentuk tashghir yang dimaksud adalah memanggil anak dengan nama kesayangannya (janganlah kamu mempersekutukan Allah, sesungguhnya mempersekutukan) Allah itu (adalah benar-benar kelaliman yang besar.") Maka anaknya itu bertobat kepada Allah dan masuk Islam." 9

Lafad يَطِظْ menunjukkan makna nasehat menyangkut berbagai kebajikan dengan cara menyentuh hati disertai penjelasan pahala dan ancamannya. ${ }^{10}$ Nasehat ini dilakukan terus menerus sebagaimana dipahami bentuk kata kerja masa kini dan akan datang. Menurut Ahmad Tafsir bahwa

\footnotetext{
${ }^{8}$ Ibid.

9 Jalaluddin al-Mahalli dan Jalaluddin al-Suyuthi, Tafsir al-Jalalain (Surabaya: Maktabah alHidayah, t.t.), 339.

${ }^{10}$ Ahmad Tafsir, Ilmu Pendidikan dalam Perspektif Islam (Bandung: Rosda Krya, 2007), 145.
} 
mauidzah itu juga berarti tadzkir (peringatan) yang memberi nasehat hendaknya berulang kali disertai keikhlasan agar nasehat itu meninggalkan kesan. ${ }^{11}$ Menurut al-Khalil, " $a l-w a$ ' $d z u$ ” adalah mengingatkan sesuatu yang bisa dirasakan oleh hati dengan cara yang baik. Dalam Lisanul al- Arab disebutkan bahwa kata mau'idzah adalah nasihat dan peringatan disertai dengan konsekuensinya. Menurut Ibnu Sayyidah, al-wa'dzu adalah peringatan kepada manusia tentang pahala dan siksa. ${ }^{12}$ Apa yang dikemukakan penulis Lisan al-Arab bahwa $a l-W a$ 'dzu adalah nasihat yang mengandung unsur targhib (memberi kabar gembira) dan tarhib(memberikan ancaman). Nasihat mendorong kepada semangat, motivasi, dan dorongan untuk melakukan kebaikan, sementara penyebutan tentang konsekuensi itu menunjukkan peringatan sebuah akibat buruk.

Sebutan يَا بُنَيَّ adalah panggilan yang menggambarkan kemungilan mengisyaratkan kasih sayang. Kehalusan ini adalah untuk menguasai anak didik agar tidak liar. Penyebutan dengan istilah anak ini bukan berarti bahwa anak itu masih kecil, namun ungkapan ini untuk menunjukkan ungkapan kasih sayang dan kelembutan kepada seorang anak. Di mata ayah, seorang anak selalu saja lebih kecil, lebih sedikit pengalamannya, dan selalu membutuhkan nasihat dari para pendahulunya, khusus mereka yang ahli ilmu dan makrifat.

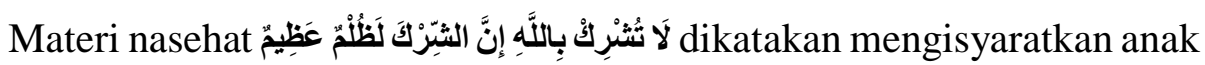
Luqman adalah kafir, ${ }^{13}$ sehingga nasehat pertama jangan menyekutukan Allah.

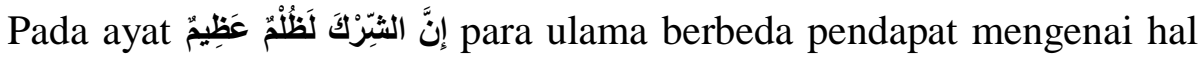
ini, apakah pernyataan ini merupakan perkataan Luqman ataukah kabar dari Allah yang terpisah dari perkataan Luqman, namun bersambung dalam satu kalimat untuk menguatkan kalimat? Pendapat pertama menganggap pernyataan itu adalah perkataan Luqman. Pendapat kedua menganggapnya sebagai kabar dari Allah, bukan perkataan Luqman, namun disambung dalam satu kalimat untuk menguatkan makna. Pendapat kedua ini diperkuat oleh hadits Ma'tsur, bahwa ketika diturunkan ayat:

\footnotetext{
${ }^{11}$ Ibid, 146.

${ }^{12}$ Ibnu Mandzur, Lisan al- 'Arab (Beirut: Dar Shadir, 2009), 466.

${ }^{13}$ Mustafa, al-Kashshaf, Juz 3 . 493
}

Dirasah, Vol. 2, No. 1, Februari 2019 


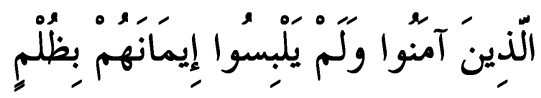

Terjemahnya: "orang-orang yang beriman dan tidak mencampurkan iman mereka dengan kezhaliman (syirik)...."(QS. al-An'aam $\{6\}: 82)$ ". ${ }^{14}$ para sahabat bertanya kepada Rasulullah, "Bagaimana mungkin kita tidak

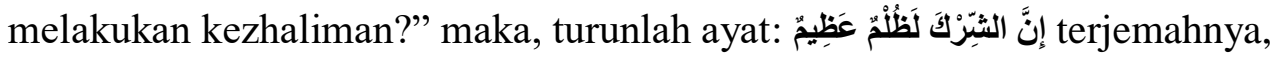
....Sesungguhnya, mempersekutukan Allah benar-benar merupakan kezhaliman yang nyata." (QS. Luqman \{31\}: 13). Dengan turunnya ayat ini, hati mereka menjadi tenang, karena memandangnya sebagai kabar dari Allah. Ketenangan itu juga bisa muncul karena Allah menyebutkan seorang hamba yang diberi sifat dengan kepemilikan hikmah dan kearifan.

Menurut al-Alusi, diriwayatkan dari Ibnu Luqman dan istrinya, bahwa keduanya adalah kafir, dan belum ada yang memberikan nasihat kepada keduanya hingga keduanya masuk Islam. Ibnu Abi Dunya men-takhrij hadits dari ar-Raqasi, lalu berkata, "Luqman terus memberikan nasihat kepada anaknya hingga dia mati." Ada ulama mengatakan bahwa anak Luqman adalah seorang muslim dan dilarang untuk melakukan syirik, sebagai peringatan untuk masa-masa yang akan datang. ${ }^{15}$ Ar-Razi menyebutkan bahwa firman Allah dalam QS. Luqman (31):13 tersebut adalah 'athaf terhadap makna ayat yang disebutkan sebelumnya. Jika ditampakkan, maka ayat tersebut dapat dimaknai bahwa Allah memberi Luqman hikmah ketika dia dijadikan orang yang bersyukur atas dirinya dan ketika dia dijadikan orang yang memberi nasihat terhadap orang lain. Demikian ini adalah alasan tingginya derajat seseorang, yaitu ketika dia secara pribadi sempurna dan sekaligus menyempurnakan orang lain.

Dari ayat di atas dapat diambil pelajaran bahwa kasih sayang, perhatian atau pemberian orang tua bukanlah mengutamakan harta benda atau tujuan dan kenikmatan duniawi kepada anaknya. Terkadang banyak orang tua, sebagai bukti kasih sayang kepada anaknya, mereka memberikan berbagai kemewahan duniawi. Secara tidak langsung orang tua seperti itu mengajarkan kecintaan kepada kefanaan dan dunia.

Bila para orang tua mencontoh Luqman bagaimana Luqman memberikan kasih sayangnya barangkali akan membentuk generasi beriman yang mempunyai kecerdasan spiritual yang tinggi dan berakhlak mulia.

\footnotetext{
${ }^{14}$ Departemen Agama RI, al-Qur'an dan Terjemahannya (Bandung: Diponegoro, 2000), 109.

${ }^{15}$ Mahmud Al-Alusi, Ruhul Ma'ani (Bairut: Dar Ihya at-Turrast al-Arabi. t.t), 85.
} 
Sebagai bentuk kasih sayangnya, Luqman melarang anaknya berbuat syirik kepada Allah SWT. Dari perintah larangan itu, penulis dapat menduga bahwa Luqman tidak memerintah anak pada usia dini tapi ketika menginjak dewasa dan mempu memahami apa itu syirik. Nasihat itu ditujukan pada anaknya yang sudah terkena perintah dan larangan Allah SWT, mengetahui surga dan neraka, dosa dan pahala.

\section{2. tafsir QS Luqman ayat 14-15}

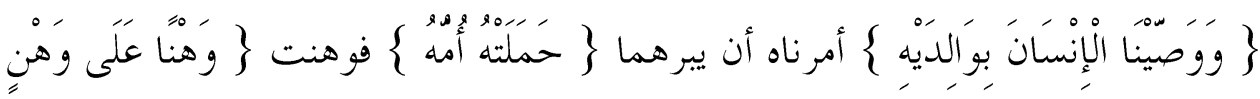

$$
\begin{aligned}
& \text { \{ أي ضعفت للحمل وضعفت للطلق وضعفت للولادة \} وفرضَالهُ \{ أي فطامه \} فِي }
\end{aligned}
$$

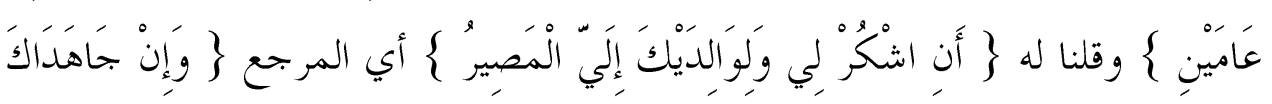

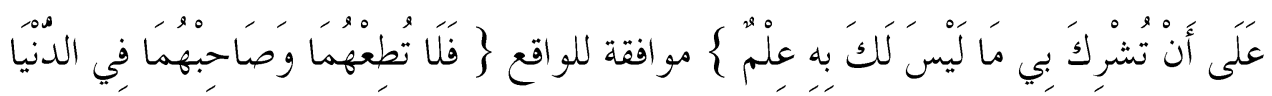

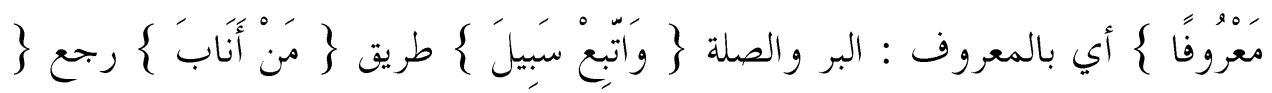

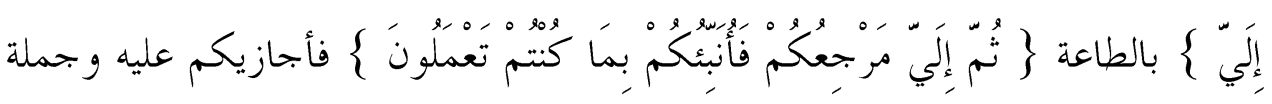

$$
\begin{aligned}
& \text { الوصية وما بعدها اعتر اض }
\end{aligned}
$$

Artinya: (Dan Kami wasiatkan kepada manusia terhadap kedua orang ibu bapaknya) maksudnya Kami perintahkan manusia untuk berbakti kepada kedua orang ibu bapaknya (ibunya telah mengandungnya) dengan susah payah (dalam keadaan lemah yang bertambahtambah) ia lemah karena mengandung, lemah sewaktu mengeluarkan bayinya, dan lemah sewaktu mengurus anaknya di kala bayi (dan menyapihnya) tidak menyusuinya lagi (dalam dua tahun. Hendaknya) Kami katakan kepadanya (bersyukurlah kepada-Ku dan kepada kedua orang ibu bapakmu, hanya kepada Akulah kembalimu) yakni kamu akan kembali. (Dan jika keduanya memaksamu untuk mempersekutukan dengan Aku sesuatu yang tidak ada pengetahuanmu tentang itu) yakni pengetahuan yang sesuai dengan kenyataannya (maka janganlah kamu mengikuti keduanya, dan pergaulilah keduanya di dunia dengan cara yang makruf) yaitu dengan berbakti kepada keduanya dan 
menghubungkan silaturahmi dengan keduanya (dan ikutilah jalan) tuntunan (orang yang kembali) orang yang bertobat (kepada-Ku) dengan melakukan ketaatan (kemudian hanya kepada Akulah kembali kalian, maka Kuberitakan kepada kalian apa yang telah kalian kerjakan) Aku akan membalasnya kepada kalian. Jumlah kalimat mulai dari ayat 14 sampai dengan akhir ayat 15 yaitu mulai dari lafal wa washshainal insaana dan seterusnya merupakan jumlah i'tiradh, atau kalimat sisipan". ${ }^{16}$

Pendapat para ulama' terhadap kedua ayat di atas:

a. Kedua ayat ini merupakan pengecualian di tengah-tengah wasiat Luqman.

b. Kedua ayat ini termasuk bagian yang diwasiatkan Luqman kepada anaknya, dan Allah menginformasiakan hal ini, karena Allah mewajibkan taat kepada kedua orang tua selama tidak dalam kemaksiatan kepada Allah.

c. Pendapat bahwa kalimat "Wa idz qala luqman li ibnihi" di mana Luqman berkata kepada anaknya, lalu kami berkata kepada Luqman tentang hikmah yang kami berikan kepadanya, "Wawasshaina al-insan biwalidaihi". Maksudnya, kami katakan kepadanya agar dia bersyukur dan kami pun berkata kepadanya "Wa wasshaina al-insana."

d. At-Thabari menyatakan bahwa kedua ayat ini diturunkan dalam kasus Sa'ad bin Abi Waqas ketika dia masuk Islam. Ibunya tidak rela dengan keislaman Sa'ad dan bersumpah untuk tidak makan dan tidak minum sampai mati atau jika dia menghendaki ibunya tidak mati, maka dia harus meninggalkan Islam. Sa'ad mengabaikan perlawanan ibunya yang terus berbuat demikian, bahkan ketika Sa'ad mengunjungi dan memberinya minum. Ketika ibunya meninggal, turunlah kedua ayat ini.

e. Ibnu Katsir menyebutkan bahwa firman Allah yang berbunyi:

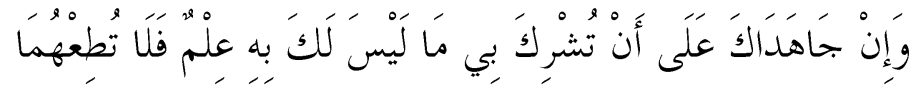

Artinya: "Dan jika keduanya memaksamu untuk mempersekutukan-Ku dengan sesuatu yang kalian tidak ada pengetahuan tentangnya, maka janganlah kalian mengikuti keduanya....." (QS. Luqman $\{31\}: 15)^{17}$

\footnotetext{
${ }^{16}$ Jalaluddin al-Mahalli dan Jalaluddin al-Suyuthi, Tafsir al-Jalalain, 339.
}

${ }^{17}$ Departemen Agama RI, al-Qur'an dan Terjemahannya, 329. 
Ayat ini diturunkan dalam kasus Sa'ad bin Malik. Berkenaan dengan sebab turunnya ayat, al-Wahidi menyebutkan bahwa kedua ayat ini diturunkan dalam kasus Sa'ad seperti yang disebutkan Thabari dan Ibnu Katsir. ${ }^{18}$

Jika kita melihat pendapat-pendapat tersebut, maka semuanya saling berdekatan dan tidak saling berlawanan. Oleh karena itu, kita bisa memahaminya sebagai berikut: berkaitan dengan pendapat pertama, maka bisa dijawab bahwa ayat ini perkecualian dalam rangka memberikan penegasan ( ta $^{\prime} \mathrm{kid}$ ) terhadap wasiat Luqman tentang larangan syirik. Di antara wasiat Luqman kepada anaknya adalah wasiat agar berbuat baik, berterima kasih, dan taat kepada kedua orang tua selain dalam kemaksiatan kepada Allah seperti yang telah diterangkan di dalam al-Qur'an. Ini juga bagian dari hikmah yang diberikan kepada Luqman seperti dijelaskan pendapat kedua dan ketiga.

Sedangkan, pendapat keempat yang menyatakan bahwa kedua ayat diturunkan dalam kasus Sa'ad bin Abi Waqas dan pendapat kelima bagwa ayat ini diturunkan dalam kasus Sa'ad bin Malik, bisa dijelaskan bahwa Sa'ad bin Abi Waqas itu tidak lain adalah Sa'ad bin Malik, seperti dikemukakan oleh Ibnu Hajar. Demikian juga disebutkan oleh Ibnu Atsir dalam kitab Asad al-Ghabah, dan pernyataan az-Zahabi dalam al-Kasyif.

Dari Hanad ibn al-Sari dari Abu al-Ahwash dari Samak ibn Harb daria Mas'ab ibn Sa'ad berkata: Ibu Sa'ad bersumpah untuk tidak makan dan minum sampai Sa'ad pindah dari agama Islam, lalu Sa'ad membangkang dan ibunya tidak mau makan dan minum sampai pingsan. Kemudian anak-anaknya datang dan memberi minum ibunya. Maka tatkala ibunya sudah siuman maka ibunya mendo'akan Sa'ad maka turunlah ayat 14-15 surat Luqman ini.19 Menurut penjelasan tafsir al.Kashahaf kemunculan ayat 14 dan 15 di sela-sela nasehat Luqman adalah ungkapan Allah sang pencerita وَوَصََنْنَا الِْنْنَنَانَ menyela nasehat guna memperkuat nasehat Luqman untuk tidak shirik yakni:

$$
\text { وَإِنْ جَاهَدَاكَكَ عَلَى أَنْ تُشْرِكَ بِي }
$$

\footnotetext{
${ }^{18}$ Abdullah al-Ghamidi, Cara mengajar Anak/Murid ala Luqman al-Hakim (Yogjakarta: sabil, 2011), 118.

${ }^{19}$ Abu Ja'far ibn Muhamad ibn Jarir al-Tabari, Tafsir al-Tabari, juz 10 (Libanon: Dar al-Kutub al-Ilmiah), 211.
}

Dirasah, Vol. 2, No. 1, Februari 2019 
Artinya, jika kedua orang tuamu mengajak dengan memaksa untuk syirik maka jangan taati. kembalimu hanya kepadaku maka jangan kau syirik dan bershukurlah padaku dan pada kedua orang tuamu. Pengikutan orang tua dalam hal ini khususnya ibu adalah betapa hak ibu untuk diterimakasihi adalah sangat besar. ${ }^{20}$

Ayat 14 dan 15 walaupun turun berkenaan dengan kasus Sa'ad ibn Abi Waqas tetapi Luqman juga menasehatkan seperti ayat ini kepada anaknya, makanya disebutkan disela-sela nasehat Luqman pada anaknya. ${ }^{21}$

Penjelasan وَفِصَالُةُ فِي عَامَيْنِ bukan berarti ibu menyusui harus dua tahun tetapi betapa susahnya ibu yang rata-rata menyusui anaknya selama dua tahun. Abu Hanifah berpendapat bahwa masa susuan yang berkaitan dengan tahrim adalah tiga puluh bulan. Ini sesuai dengan firman Allah yang berbunyi:

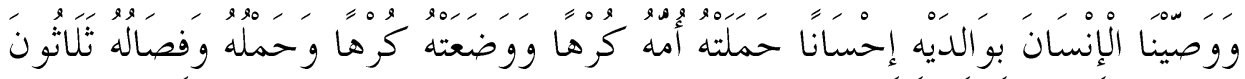

Artinya: "Kami perintahkan kepada manusia supaya berbuat baik kepada dua orang ibu bapak, ibunya mengandungnya dengan susah payah, dan melahirkannya dengan susah payah (pula).mengandungnya sampai menyapihnya adalah tiga puluh bulan....." (QS. al-Ahqaaf $\{46\}: 15){ }^{22}$

Maksud ayat ini adalah Allah menyebutkan dua hal dan menetapkan satu masa tertentu sebagai masa hitungan yang sempurna, seperti penundaan dua buah utang. Misalnya, seseorang berkata, "aku menangguhkan piutangku atas si fulan dan si fulan selama setahun." Ini dipahami bahwa satu tahun itu diperuntukkan bagi penundaan kedua utang itu. Menurut 'Aisyah, seorang anak tidaklah berada di dalam kandungan ibunya melebihi dari dua tahun, sehingga masa penyapihan ini berdasarkan zhahirnya. Apa yang disebutkan di sini adalah masa yang paling sedikit.

Penjelasan وَاتَّْعِ سَبِيَلَ مَنْ أَنَابَ إلَّيَ artinya, dan ikutilah jalan orang yang kembali dari syiriknya bukankah kepadaku kamu akan dikembalikan setelah mati dan

\footnotetext{
${ }^{20}$ Mustafa, al-Kashshaf, Juz 3, 495.

${ }^{21}$ Abu Ja'far ibn Muhamad ibn Jarir al-Tabari, Tafsir al-Tabari, 210.

${ }^{22}$ Departemen Agama RI, al-Qur'an dan Terjemahannya, 402.
} 
akan kuberitahu apa yang kamu kerjakan, maka jangan sampai perbuatanmu syirik.

Ayat ini mengandung pengertian bahwa manusia wajib berterima kasih dengan cara berbakti kepada orang tua khususnya ibu dengan alasan karena telah susah payah melahirkan dan menyusuinya dan manusia juga wajib berterima kasih kepada Allah dengan tidak shirik sebab semua akan kembali kepada Allah. Ayat ini juga menjelaskan batas berbakti kepada orang tua sepanjang tidak mengajak mendurhakai Allah (syirik).

\section{3. tafsir QS Luqman Ayat 16}

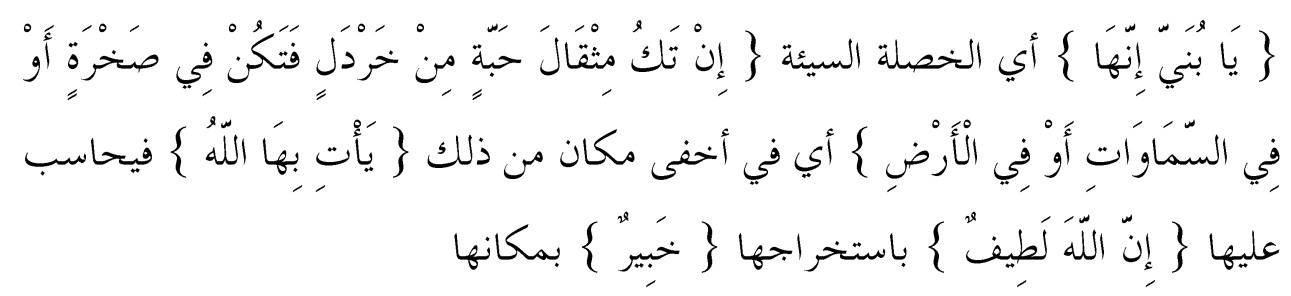

Artinya: ("Hai anakku, sesungguhnya) perbuatan yang buruk-buruk itu (jika ada sekalipun hanya sebesar biji sawi, dan berada dalam batu atau di langit atau di bumi) atau di suatu tempat yang paling tersembunyi pada tempat-tempat tersebut (niscaya Allah akan mendatangkannya) maksudnya Dia kelak akan menghisabnya. (Sesungguhnya Allah Maha Halus) untuk mengeluarkannya (lagi Maha Waspada) tentang tempatnya. ${ }^{23}$ (QS. Luqman 16)

Ayat di atas mengandung pengertian bahwa Luqman mewasiatkan kepada anaknya agar selalu waspada terhadap rayuan yang telah mengajak dan mempengaruhi manusia melakukan perbuatan-perbuatan dosa. Apa yang dilakukan manusia sejak dari yang kecil, yang tampak dan yang tidak, yang terlihat dan yang tersembunyi baik dilangit atau dibumi, pasti diketahui oleh Allah SWT.

${ }^{23}$ Jalaluddin al-Mahalli dan Jalaluddin al-Suyuthi, Tafsir al-Jalalain, 339.

Dirasah, Vol. 2, No. 1, Februari 2019 


\section{Tafsir QS Luqman Ayat 17}

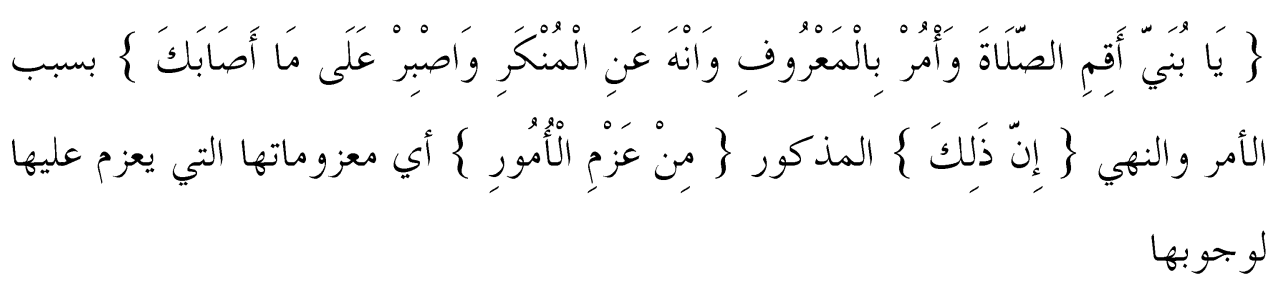

Artinya: (Hai anakku, dirikanlah salat dan suruhlah manusia mengerjakan yang baik dan cegahlah mereka dari perbuatan mungkar serta bersabarlah terhadap apa yang menimpa kamu) disebabkan amar makruf dan nahi mungkarmu itu. (Sesungguhnya yang demikian itu) hal yang telah disebutkan itu (termasuk hal-hal yang ditekankan untuk diamalkan) karena mengingat hal-hal tersebut merupakan hal-hal yang wajib. ${ }^{24}$

Pada ayat di atas terdapat kandungan makna sebagai berikut:

a. perintah Luqman kepada anaknya untuk mendirikan sholat

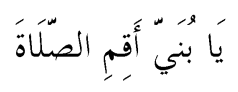

Artinya: "Wahai anakku, dirikanlah shalat....."

Setelah Luqman memerintahkan anaknya mengesakan Allah (tauhidullah)-hal yang wajib bagi setiap mukallaf-, kemudian Luqman memrintahkan anaknya agar mendirikan shalat sebagai ibadah yang paling sempurna. $^{26}$

b. perintah Luqman untuk amar ma'ruf nahi munkar

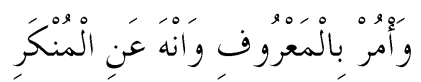

Artinya: “... Dan suruhlah (manusia) mengerjakan yang baik dan cegahlah(mereka) dari perbuatan yang mungkar....". ${ }^{27}$

Dalam Tafsir Thabari di jelaskan tentang makna ayat ini "Allah memerintahkan manusia agar taat dan mengikuti perintah-Nya dan

\footnotetext{
${ }^{24}$ Ibid.

${ }^{25}$ Departemen Agama RI, al-Qur'an dan Terjemahannya, 458.

26 al-Ghamidi, Cara mengajar Anak/Murid.., hal. 211.

${ }^{27}$ Departemen Agama RI, al-Qur'an dan Terjemahannya, 460.
}

Dirasah, Vol. 2, No. 1, Februari 2019 
melarang mereka untuk durhaka, malakukan kemaksiatan, atau melakukan hal-hal yang dilarang dan diharamkan-Nya." 28

c. sabar atas segala yang menimpa

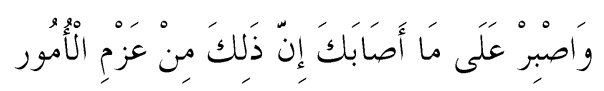

Artinya: ... Dan bersabarlah terhadap apa yang menimpa kamu. Sesungguhnya, yang demikian itu termasuk hal-hal yang diwajibkan (oleh Allah). (QS. Luqman $\{31\}: 17)^{29}$.

Makna dari kandungan ayat ini adalah, hendaklah manusia bersabar terhadap cobaan dan rasa berat dalam melaksanakan apa yang diperintahkan, kususnya dalam mendirikan shalat dan amar ma'ruf nahi munkar. Wasiat kesabaran ini datang berkenaan dengan tiga masalah ini secara khusus karena nilai pentingnya yang luar biasa.

Mendirikan shalat, dengan menyempurnakan dan menjaga pelaksanaannya tepat waktu sesuai dengan seluruh rukun, wajib, dan sunnahnya, kadang berat untuk dilakukan. Allah berfirman:

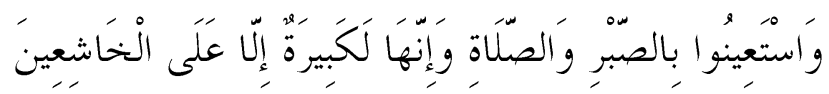

Artinya: ...Jadikanlah sabar dan shalat sebagai penolongmu. Dan, sesungguhnya yang demikian itu sungguh berat, kecuali bagi orang-orang yang khusuk.(QS. al-Baqarah $\{2\}: 45)^{30}$

Pelaksanaan amar ma'ruf nahi munkar merupakan kebutuhan yang tidak mudah untuk dijalankan kerena akan berhadapan dengan perlawanan dari pihak lain sehingga proses ini akan melelahkan. Menurut Ibnu Jabir "makna Bersabarlah atas apa yang menimpamu! Adalah dalam hal Amar ma'ruf nahi munkar. Jika kalian memerintahkan kepada kebaikan dan mencegah kemungkaran, kemudian Anda menghadapi penderitaan dan gangguan, maka bersabarlah., ${ }^{31}$

\footnotetext{
${ }^{28}$ Abu Ja'far ibn Muhamad ibn Jarir al-Tabari, Tafsir al-Tabari,73.

${ }^{29}$ Departemen Agama RI, al-Qur'an dan Terjemahannya, 329. .

${ }^{30}$ Ibid, 7.

${ }^{31}$ Mahmud al-Alusi, Ruhul Ma'ani, 89.
}

Dirasah, Vol. 2, No. 1, Februari 2019 


\section{Penutup}

Karakteristik pendidikan Luqman Hakim sebagaimana surat Luqman ayat 1317:

1. Pendidikan Luqman Hakim tentang tauhid seperti larangan syirik (penyucian jiwa dari sifat angkuh dan sombong).

2. Moralitas individual seperti syukur, sabar, menjaga diri, berbuat baik kepada Ibu-Bapak dan mendirikan shalat.

3. Moralitas sosial yang di implementasikan dengan praktik Amar ma'ruf Nahi munkar.

\section{Daftar Pustaka}

Al-Alusi, Mahmud. Ruhul Ma'ani. Bairut: Dar Ihya at-Turrast al-Arabi. t.t.

Al-Ghamidi, Abdullah. Cara mengajar Anak/Murid ala Luqman al-Hakim. Jogjakarta: Sabil. 2011.

Al-Suyuthi, Jalaluddin. Tafsir al-Jalalain, Surabaya: Maktabah al-Hidayah. t.t.

Al-Tabari, Abu Ja'far ibn Muhamad ibn Jarir. Tafsir al-Tabari, juz 10. Libanon: Dar al-Kutub al-Ilmiah. tt.

Arikunto, Suharsimi. Prosedur Penelitian: Suatu Pendekatan Praktek. Jakarta: Rineka Cipta. 1997.

Departemen Agama RI, al-Qur'an dan Terjemahannya. Bandung: Diponegoro. 2000.

Mandzur, Ibnu. Lisan al- 'Arab, juz 7

Mardalis. Metode Penelitian Suatu Pendekatan Proposal. Jakarta, Bumi Aksara. 1995.

Mustafa, al-Kashshaf, Juz 3.

Sanjaya, Wina. Strategi Pembelajaran. Jakarta: Kencana Prenada Group. 2008. 
Saylor, Ward \& Hooper, Helen. Sumber Primer, Sekunder \& Tersier, terj. Darmanto (t.t., t.p., t.t.) (darmanto99.multiply.multiplycontent.com), diakses tanggal 16 Juni 2012

Tafsir, Ahmad. Ilmu Pendidikan dalam Perspektif Islam. Bandung: Rosda Karya. 2007.

"Pendidikan Luqman", Republika on line, http://www. Republika.co. id, diakses tanggal 8 juni 2012

Copyright (C 2019 Journal Dirasah: Vol. 2, No. 1, Februari 2019, p-ISSN: 2615-0212, e-ISSN; 2621-2838

Copyright rests with the authors

Copyright of Jurnal Dirasah is the property of Jurnal Dirasah and its content may not be copied or emailed to multiple sites or posted to a listserv without the copyright holder's express written permission. However, users may print, download, or email articles for individual use.

https://ejournal.iaifa.ac.id/index.php/dirasah

Dirasah, Vol. 2, No. 1, Februari 2019 